Aletria, Belo Horizonte, v. 31, n. 2, p. 223-243, 2021

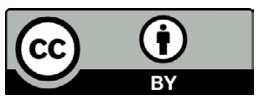

\title{
Aproximação à escola discursiva dos Robinsons
}

\section{Approaching Robinsons' Discursive School}

\author{
Daniel Bonomo \\ Universidade Federal de Minas Gerais (UFMG), Belo Horizonte, Minas Gerais / Brasil \\ drbonomo@gmail.com \\ http://orcid.org/0000-0003-4516-7683
}

Resumo: O objetivo do texto é contribuir para a definição de uma escola discursiva fundada por Daniel Defoe em Robinson Crusoé, há trezentos anos. A hipótese de que o título inaugura uma tradição importante para o desenvolvimento do romance como gênero é sustentada pela observação de sua economia formal e de seus prováveis efeitos de leitura, que se transformam no tempo e nas diferentes realizações que repõem o modelo em novos contextos, mais ou menos distantes do original. Assim aparecem, aqui, além do primeiro e do segundo Robinson de Defoe, interpretações de $O$ Robinson suiço (Johann David Wyss), A escola dos Robinsons (Júlio Verne), Suzana e o Pacifico (Jean Giraudoux), Sexta-Feira ou os limbos do Pacifico (Michel Tournier), A vida sexual de Robinson Crusoé (Michel Gall) e A invenção de Morel (Adolfo Bioy Casares), que representam configurações narrativas desiguais, mas relevantes para o entendimento em perspectiva das continuidades em jogo.

Palavras-chave: Daniel Defoe; Robinson Crusoé; robinsonada; teoria narrativa.

Abstract: This essay aims to characterize a discursive school founded by Daniel Defoe with the publication of Robinson Crusoe three hundred years ago. The hypothesis that Robinson Crusoe inaugurates an important tradition for the development of the novel as a genre is supported through the observation of its formal economy and its presumed reading responses, which change over time, as shown by comparisons of different narratives that restore somehow the original model of Defoe in new contexts, such as The Swiss Family Robinson (Johann David Wyss), Godfrey Morgan (Jules Verne), Suzanne and the Pacific (Jean Giraudoux), Friday or the other Island (Michel 
Tournier), The Sexual Life of Robinson Crusoe (Michel Gall), and The Invention of Morel (Adolfo Bioy Casares). The dissimilarity between these titles contributes to the understanding of the continuities at stake as well as to outlining the distinctiveness of Defoe's fiction in perspective.

Keywords: Daniel Defoe; Robinson Crusoe; robinsonade; narrative theory.

Este ensaio expande uma leitura de Robinson Crusoé publicada recentemente ${ }^{1}$ e procura verificar sua aplicação a um número reduzido, mas exemplar, de títulos ligados à imensa tradição de desdobramentos do texto original de Daniel Defoe. A leitura em apreço circunscreveu um vínculo entre as ideias de aborrecimento e entretenimento mediante uma análise da economia formal e dos efeitos de leitura que ela pressupõe na composição da narrativa do célebre náufrago e ilhéu por quase três décadas. Essa leitura é parte de pesquisa maior, que investiga como o gênero romanesco organizou, desde os seus inícios, arranjos discursivos que sugerem leituras mais ou menos prazerosas, em todo caso historicamente determinadas. Ela implica o entendimento do romance como um gênero inclusivo, por seu processo híbrido e integrativo, e extensivo, por seus recursos amplificantes, que dispõem qualidades diferentes de ação e inação. Discutem-se, portanto, as diferentes dosagens, as formas de distribuir a matéria narrada no tempo da narração e as possíveis reações do leitor a essas formas. A qualidade afetiva dessas reações, agradáveis ou não, para simplificar, requer duas premissas. A primeira delas associa em planos simultâneos a afirmação do romance como gênero e o assentamento da burguesia como classe administrada. No século XIX, como se sabe, o romance foi em larga medida a epopeia da gente média, pouco heroica, assim como o realismo histórico favoreceu a parcimônia das relações e o investimento em modalidades romanescas refratárias à rotina aburguesada apenas confirmou, em negativo, essa mesma tendência. A reação modernista, o cansaço de uma geração com personagens burgueses e marquesas que saíam às cinco (aludindo à frase conhecida de Paul Valéry), por sua vez, deu uma interpretação conclusiva a esse movimento. Já a segunda premissa tem a ver com essa mesma resposta modernista ao século XIX em tempos de aceleração enfática

\footnotetext{
1 Trata-se do ensaio "Experimentum in insula: Robinson Crusoé nas origens do aborrecimento", de minha autoria, publicado em 2018 na revista Literatura e Sociedade.
} 
das experiências pessoal e coletiva, ligada à própria condição moderna (ROSA, 2016). À pesquisa neste ponto interessam não só os regimes temporais de uma cultura ansiosa por estímulos hoje disseminada em hábitos corriqueiros, como também uma resistência a esse quadro que atribui sentidos tediosos a realidades lentas. Nesse contexto, a admissão do aborrecimento tem um sentido positivo como recusa à simplificação ideológica que prejudica a inteligência do prazer na leitura.

Recuperando a leitura de Robinson Crusoé mencionada, cabe dizer como e por que ela adquire relevância na pesquisa em questão. Aqui, as atualidades na história de Robinson que interessam não são as que se veem mais frequentemente discutidas nela como atualidades, ou seja, as importantes dimensões problemáticas e críticas do colonialismo europeu e do individualismo. Essas dimensões importam aqui também, mas indiretamente, na medida em que figuram, aliás, um sujeito irrealista. Quer dizer, o irrealismo na história de Robinson não está nas aventuras entre piratas e selvagens, mas no fato de que, anos e anos sozinho, ilhado sem poder mais, depois de algum tempo perfeitamente instalado e seguro, não se queixa de tédio, jamais se aborrece. Este avesso reprimido do tédio chama a atenção, este avesso que assedia o enredo e cuja latência aumenta tão mais recalcado pareça, ao ponto de o personagem justificar por que nunca se entediou (DEFOE, 1994). Contudo, mais importante aqui, a ausência de representação do aborrecimento não suprime a possibilidade de aborrecimento na representação, não há relação necessária entre uma coisa e outra. Assim como a representação de uma realidade aborrecida pode ser prazerosa, a de uma realidade prazerosa pode ser aborrecida. $\mathrm{O}$ raciocínio é até certo ponto óbvio, ainda que sejam vários os fatores que entram na equação e a dificultam. No texto de Defoe, o que relaciona as duas coisas e vincula a presença negativa do tédio com um suposto aborrecimento da representação é, numa palavra, a ilha. Não a metáfora, não a imaginação nem o imaginário da ilha, que são produtivos nas literaturas antiga e moderna, e particularmente proveitosos nas letras inglesas não por acaso; mas as circunstâncias concretas da ilha, as de tempo e espaço, que no romance decidem os andamentos entre ação e inação. A análise de Robinson Crusoé depende, nesse sentido, de examinar a experiência narrativa como um "experimento insular", que, muito esquematicamente, se divide em três etapas: a primeira até o naufrágio, a segunda na ilha, a terceira na ilha também, mas diferente. Essa terceira etapa inicia com a visão da pegada na areia e formaliza 
um movimento de conciliação das etapas anteriores rumo à solução do enredo. Na primeira etapa, antes da ilha, predominam a aventura, a errância, o dado imprevisível. Na segunda, na ilha, entra em cena a previdência alerta e atuante, para a manutenção da vida e a conquista pelo trabalho da comodidade, excluindo em larga medida o dado imprevisível. Sem representar nenhuma forma de tédio, o aborrecimento da representação acompanha essa passagem da primeira para a segunda etapa como transformação qualitativa da ação em atividade, da surpresa em cálculo, do incidente em rotina. Seu aspecto construtivo são os acúmulos nominais e verbais compondo catálogos de utensílios e tarefas, e a tentativa de serialização do tempo no diário de Robinson, que, além disso, faz "sérias reflexões" não apenas com propósitos religiosos, mas, de uma perspectiva narrativa, para o tratamento adequado da massa temporal infinita na ilha. Entretanto, o diário será abandonado e as reflexões aparecerão com frequência em resumo, o que revela o tipo de controle das formas que interessa impor às formas que vão assumindo controle. A análise estrutural da narrativa e das construções no nível da frase mostra que acima de tudo são determinantes as temporalidades do relato, que escolhem suas durações, ou seja, o que se expande e o que se abrevia no tempo de sobra da ilha. Por exemplo, o narrador não expõe em detalhes como levou quarenta e dois dias para extrair uma tábua de um tronco, ao passo que, antes de chegar à ilha, valorizou cada instante da tempestade que levou o seu navio a pique. Ele mostra assim um grau elevado de consciência dos prováveis efeitos da narrativa, para além dos trechos em que, recorrendo à tradicional convenção retórica, diz não contar algo detalhadamente porque enfadaria o leitor. Quando faz o seu personagem se deparar com a famosa pegada, essa consciência é clara. O efeito poderoso da cena é visível ao mesmo tempo que o domínio narrativo de Defoe, que retarda e explora as consequências previstas no acontecimento espantoso. Do conflito com os nativos que deixam escapar Sexta-Feira em diante, a história de Robinson não ficará mais por muito tempo sem o tipo de ação audaz, a mesma de antes da ilha, atenuada na ilha.

Sem reproduzir integralmente a leitura de Robinson Crusoé em questão, suas conclusões provisórias ficam esboçadas da seguinte maneira: nas origens modernas do romance, o título de Defoe expõe narrativamente alguns dos seus mais importantes conflitos no que respeita à composição que prevê seus possíveis efeitos de prazer e aborrecimento no leitor 
mediante uma economia formal dividida entre aventura e cotidiano, ação e reflexão, em construções de qualidade diversa. Do conjunto, resulta uma organização narrativa que favorece o polo da ação e com ele efeitos afins à ideia de entretenimento, sem eliminar, contudo, os elementos associáveis ao polo contrário da inação. O termo "variedade" (variety), com que Defoe propagandeou em quase todos os prefácios dos seus livros uma espécie de convite à fruição prazerosa ${ }^{2}$ essa variedade é regulada por disposições textuais que negociam efeitos de leitura conflitantes no tempo da representação. Nesse sentido, o romance de Defoe ora tricentenário e popular desde a sua publicação primeira parece indispensável à reflexão sobre os caminhos trilhados pelo gênero e expandidos em diversas formas de ficção. Não se ignora com isso a historicidade dos efeitos de leitura pressupostos, quer dizer, não se ignora que o prazer na leitura de certos elementos narrativos do passado apenas se aborreceu mais tarde, assim como outros elementos podem ter, em outros contextos, seu interesse renovado, e que há um fator pessoal, a relação particular de cada leitor com o texto que eventualmente lê. Contudo, a historicidade dos efeitos de prazer e aborrecimento também reside nos textos, na observação em perspectiva, que sugere hipóteses sobre como assuntos e formas narrativas preservam ou não interesse e que tipo de interesse. A proliferação de Robinson Crusoé, dos seus esquemas em versões e revisões de qualidade diversa, é lugar privilegiado para a observação dessas relações. Além disso, a sua influência não parece limitada à série de adaptações da história de Robinson. Evitando fazer teleologia, isto é, evitando compreender Robinson Crusoé como causa exclusiva de consequências múltiplas, e sem ignorar a reconhecida dependência do romance de Defoe a modelos anteriores (HUNTER, 2018), seria o caso de pensá-lo, hipoteticamente, como obra de um "fundador discursivo", nos termos de Foucault (2006, p. 280), como "possibilidade e regra de formação de outros textos". Pensá-lo, portanto, não como um primeiro romance, mas como a produção de um enquadramento ficcional decisivo, cuja importância dos desdobramentos termina por suplantar em certo sentido a relevância dos inúmeros aproveitamentos do passado que o informam.

\footnotetext{
${ }^{2}$ A tradução dos principais prefácios dos romances de Defoe pode ser lida no livro de Sandra Guardini Vasconcelos, A formação do romance inglês (2007).
} 
Essa hipótese não é recomendada pelo próprio Foucault, que distinguiu, como se sabe, entre um "simples" autor de romances e autores como Marx e Freud, que possibilitaram uma infinitude de discursos depois deles. Um autor de romances, para Foucault (2006), não funda uma tradição discursiva senão pela reposição contínua de variações muito semelhantes ao modelo. Ele dá o exemplo da escritora inglesa Ann Radcliffe, que inaugura um tipo, o do romance de terror, imitado e repetido à exaustão, mas por repetições e imitações que mantêm mais semelhanças do que diferenças em relação à fonte. Já autores como Marx e Freud, segundo Foucault (2006), abrem um campo discursivo como quem abre uma disciplina, em cuja continuidade se veem mais diferenças do que repetições e variações. Como pensar Defoe aqui? Não parece exato considerá-lo como um fundador discursivo caso seja preciso, para tanto, identificá-lo com os nomes e os significados dos nomes de Marx e Freud. Mas, se se aproxima Defoe do que Foucault diz sobre Ann Radcliffe, tampouco é satisfatório. O autor de Robinson Crusoé não inaugura apenas uma modalidade. As robinsonadas, já diversificadas por si sós, não são as únicas herdeiras de Defoe, ainda que sejam as mais imediatas. Sem pretender concluir essa questão difícil, arrisca-se mesmo assim expandir aqui a leitura de Robinson Crusoé abreviada atrás, insistindo na originalidade fundamental de Defoe. A ideia é observar agora diferenças de economia formal no interior mesmo da tradição dos Robinsons, com exemplos mais próximos ou mais distantes do original, ponderando seus efeitos de leitura pressupostos. Serão feitas abordagens rápidas de um conjunto pequeno mas representativo, com o objetivo de aproveitar do exercício comparatista, admitindo que se sacrificam especificidades em benefício do todo.

A começar pelo próprio Defoe, que, no mesmo ano de 1719, continuou a história de Robinson. The Farther Adventures ou As novas aventuras de Robinson Crusoé: que constituem a última parte da sua vida e os relatos estranhos e surpreendentes das suas viagens através de três partes do globo narram sua volta à ilha e episódios na África e no Oriente, até o retorno à Inglaterra, e compõem um excelente livro. Em parte porque as surpresas do título não tardam. Logo no início, após uma enfiada de justificativas para voltar à vida aventuresca, desponta o gênio imaginativo do autor com a cena impressionante de um navio em chamas em alto-mar. Na sequência, Robinson e demais embarcados salvam uma tripulação de franceses, antes de seguirem viagem. Ao chegarem à 
ilha do livro anterior, começam os relatos de atualização. Defoe dedica longos capítulos à história dos eventos ocorridos na ilha de Robinson após sua partida. Como se sabe, lá haviam ficado alguns espanhóis e ingleses. A convivência entre eles não foi pacífica, muito menos facilitada pelas visitas indígenas. Isto significa que não falta ação ao longo relato de atualizações. Há inclusive batalhas, bem narradas, entre europeus e nativos. Contudo, a presença de ação não garante, ao que tudo indica, o interesse da leitura neste passo. Um dos motivos para que se pressinta isso deve ser a comparação que se impõe ao leitor com a inevitável memória dos tempos de Robinson na ilha. Não se lê o mesmo encanto nos eventos atualizantes porque já nada ocorre como da primeira vez. Entretanto, a razão principal do provável desinteresse no trecho talvez seja outra: é que, embora estejam próximos, não há Robinson nem Sexta-Feira nesses relatos. Por uma espécie de comparação que se impõe conscientemente ou não, os espanhóis e ingleses resultam fracos como personagens, não atendem às expectativas presumíveis do leitor, que pode ressentir, nestas condições, das figuras mais características de Defoe.

$\mathrm{O}$ restante do texto dedicado à ilha original em The Farther Adventures trata do estabelecimento da colônia. Entram em cena, de um lado, a vocação administrativa de Defoe, de outro, a reflexão. $\mathrm{O}$ segundo Robinson é rico em "reflexão", no sentido que o termo assume em Defoe, ou seja, como religião e moral, que aliás se refletem no livro muito historicamente, pelo contraste entre valores protestantes e católicos e pelo contato com culturas não europeias. A propósito, um episódio marcante no segundo Robinson é o massacre de nativos em Madagascar, ao qual se opõe o narrador sem outro sucesso que fazer ver a barbárie dos seus compatriotas. De resto, as aventuras subsequentes, com as passagens de Robinson pela China e pela Sibéria, por atraentes que pareçam, são prolongações meio cansativas. Já se observou, nesse sentido, que o segundo Robinson não se compara em efeito com o primeiro porque nele o autor, a serviço da alegoria espiritual, sobrepõe suas intervenções conceituais ao trabalho imaginativo (CUNHA, 1989). As aventuras viram um pretexto desse modo para a reflexão excessiva do autor que termina por transformar o personagem em figurante e assim prejudica o equilíbrio da composição. Entretanto, é preciso também considerar que a promessa exótica do périplo de Robinson até certo ponto falha em compensar as expectativas que possivelmente cria porque na verdade é algo secundário na feição particular deste personagem e na 
força do esquema que inaugura. Para o leitor, talvez fique a sensação última de que essa escolha pela volta ao mundo só faz mesmo revelar que o personagem está fatalmente vinculado à ilha que o celebrizou, assim como a sua tradição exigirá, daí em diante, outras ilhas. Portanto, ainda que o segundo Robinson procure, à semelhança do primeiro, dosar ação e reflexão, e repita procedimentos bem-sucedidos da primeira parte, ele não refaz a experiência do anterior no que ela tem de essencial, o que talvez caiba não a esta continuação assinada pelo próprio Defoe, mas àqueles que sentiram a necessidade de reprisar os seus fundamentos em condições renovadas.

O exemplo seguinte, O Robinson suiço (Der schweizerische Robinson), do pastor Johann David Wyss (1743-1818), é relevante nesse sentido. Escrito na década final do século XVIII e editado por seu filho Johann Rudolf em 1812, Wyss deu ao século XIX a versão mais pedagógica do esquema robinsoniano. Assim como sua fonte, a história de Wyss gerou traduções e reproduções inúmeras. A princípio inventada para os próprios filhos, a narrativa de Wyss é um capítulo fundamental na transposição do modelo de Robinson para o universo da leitura infantil com fins educativos. Na esteira do célebre Emílio, cujo primeiro e único livro por um bom tempo deveria ser, segundo Rousseau, Robinson Crusoé, e dando seguimento nesse sentido às iniciativas anteriores de Johann Karl Wezel e Joachim Heinrich Campe, responsáveis pelas primeiras versões da história de Defoe em língua alemã, O Robinson suiço de Wyss alcançou enorme e duradoura repercussão, passando por um processo de alterações do original século XIX adentro sem muito paralelo na história literária (SEELYE, 1990). Assim mesmo, sua narrativa mantém, com ou sem as adulterações de tradutores e editores, o mesmo padrão que alinha naufrágio, sobrevivência, trabalho, conquista de comodidade e um desenlace compensador. A filiação ao modelo é observada de perto também no que respeita ao predomínio de uma ética da ação ancorada em racionalismo religioso, ainda que se percebam diferenças importantes, como a ausência, no texto de Wyss, de uma força introspectiva, uma inquietação íntima, que comunica, no Robinson de Defoe, os seus medos à sombra de um Deus que o faz penitente e devedor. Esse Deus não se vê no texto de Wyss, que, de resto, elimina dificuldades de toda sorte.

Porém, com relação ao original, a mudança de fato significativa em $O$ Robinson suiço está na substituição do personagem solitário pelos seis membros de uma família, um casal e quatro filhos. A situação 
adéqua-se como luva à mão didática e à previsão de um público jovem, que aí se reconhece. Não é difícil imaginar como a presença de uma família transforma, além disso, a construção narrativa. Na presença de personalidades distintas, ganham espaço o diálogo e a ação interativa. A vantagem, em tese, é dramática. Mas, desde a cena inicial do naufrágio, o drama é tímido. A história começa com a família a salvo na ilha após tempestade e naufrágio breves e objetivos. As crises previstas na situação difícil da ilha são no geral reduzidas. O que constrói a ação nesse sentido são soluções atrás de soluções, numa terra livre de selvagens e na qual abundam variedades vegetais e animais como em nenhum lugar conhecido, todas mais ou menos à disposição dos empreendimentos familiares. Mais que arranjar conflitos, portanto, a história de isolamento da família, com sua natureza variada e exemplar, faz as vezes de uma enciclopédia científica e moral ilustrada. Assim, o teor pedagógico avulta mediante exemplos virtuosos, na medida em que decresce no conjunto o teor aventuresco e quase desaparece a dimensão do risco. Para a leitura interessada em verificar os atuais efeitos aborrecidos do texto, eles residem aí, nem tanto pelo envelhecimento das lições que encerra, mas pela constância imperturbável, pela uniformidade edificante exigida em todas as atividades familiares, que tem por consequência uma espécie de harmonia monótona ou monotonia harmônica, aplainando personagens talvez felizes demais. Contudo, um leitor atual com interesses aborrecidos não é, está claro, o leitor pressuposto no texto de Wyss e tampouco responde desse modo às qualidades que o celebrizaram historicamente. Um leitor atual de Wyss testemunha, quando muito, a passagem do tempo, como fez J. Hillis Miller (2004, p. 79), contrapondo, em depoimento, a sua experiência de leitura de $O$ Robinson suiço aos dez anos de idade, a que chamou de "allegro reading", à leitura madura, que qualificou de "lento reading". Nesta, em vez do sentimento mágico vivenciado na infância, sobressaíram, desconfortáveis, as camadas ideológicas do texto e certo incômodo causado pela quantidade elevada de orações e pela matança de animais perturbando o desejo de um acampamento ameno. A existência hoje de um jovem interessado por estas centenas de páginas didáticomorais de Wyss (mais de oitocentas nos dois tomos de uma antiga edição franco-brasileira) é discutível. Talvez só existam ainda (alguns poucos) leitores interessados nos aspectos histórico-formais da obra do pastor suíço e da sua prole de traduções. Não obstante, Wyss sobrevive de algum modo nos mais recentes Robinsons para jovens. Precisamente 
suas conciliações, seus entendimentos, a tendência para a saída fraterna, agora transformada em aliança cordial com bichos e piratas. ${ }^{3}$

No elogio feito por Charles Nodier ([18--?]) para introduzir a tradução francesa de $O$ Robinson suiço de Élise Voïart (1837) reproduzido na edição franco-brasileira -, Wyss superaria Defoe porque substitui o personagem solitário por um pai, uma esposa, uma família. $\mathrm{O}$ argumento é majoritariamente moral, quer valorizar acima de tudo a função pedagógica do texto. "Não procureis nem nos romances, nem no que de mais especial se tenha escrito inspirando uma doce filantropia esclarecida pela ciência, um código de educação física, intelectual e moral, preferível a este", diz Nodier ([18--?], p. iv). Aí se vê o leitor histórico, isto é, aquele leitor previsto no sistema de valores do texto que Wyss pôs em cena e que seus tradutores foram atualizando. Aí se vê o leitor a quem se dirigia a "correção" no Robinson suiço do exemplo egoísta do Robinson inglês. No entanto, sem a presença desse leitor histórico e hipotético, e de um ponto de vista estético, o Robinson de Wyss fica muito prejudicado, porque, em síntese, a ênfase no propósito educativo redunda por fim em simplificação romanesca. A novidade de uma casa na árvore, o encanto de uma gruta de cristais, um jeito original de obter cocos atirados por macacos das alturas, por atraentes que pareçam, são também acessórios na escola dos Robinsons, não sustentam o edifício narrativo, que acusa, em Wyss, alguma deficiência estrutural. Mas insistir na apreciação negativa da qualidade literária do texto de Wyss pode resvalar no equívoco de dar peso excessivo a um critério inapropriado, e pode obliterar, além disso, que foram sobretudo os seus Robinsons os responsáveis por motivar as principais robinsonadas oitocentistas, como Masterman Ready (1841), de Frederick Marryat, e The Coral Island (1857), de R. M. Ballantyne. Esses dois livros populares, também comprometidos com o missionarismo colonialista do Império Britânico, de resto apontaram, como propôs Susan Naramore Maher (1988), para uma inflexão na modalidade das robinsonadas juvenis rumo à aventura em si, distanciando a oportunidade da leitura evangélico-pedagógica. Logo, os Robinsons de Wyss foram importantes para a manutenção da escola e suas transformações, que devem atender às mudanças no gosto, de um lado, mas também ao desenvolvimento de uma literatura popular que se

\footnotetext{
${ }^{3}$ Penso no filme de animação computadorizada, As aventuras de Robinson Crusoé, lançado em 2016, e no livro de Peter Sís, Robinson, de 2017.
} 
aperfeiçoa como técnica e cujas narrativas já não interessam apenas aos jovens. Nada comprova melhor essa ideia do que a obra de Júlio Verne. Júlio Verne desenvolveu e aperfeiçoou a narrativa de imaginação aventuresca e extraordinária em praticamente toda a segunda metade do século XIX, até inícios do XX, incluindo em sua extensa obra ao menos meia dúzia de robinsonadas. Ele escreveu, aliás, uma espécie de continuação para a história da família suíça de Wyss, chamada Seconde patrie, publicada em 1900. Outras das suas robinsonadas são $A$ ilha misteriosa (1875), Dois anos de férias (1888) e O tio Robinson, história que permaneceu inédita até 1992. Publicou também em 1882 A escola dos Robinsons, que se escolheu aqui não só pelo título, que sugere a ideia do ensaio, mas também por uma nota pitoresca vista no jornal Folha de $S$. Paulo, em 10 de dezembro de 2009: "Conheça o clássico de Júlio Verne que escola em São Paulo jogou no lixo”. O clássico no caso é $A$ escola dos Robinsons, no lixo de uma escola em Bauru, interior de São Paulo. Não há detalhes. Não houve pelo visto uma investigação. Os detalhes são de toda forma dispensáveis aqui. $\mathrm{O}$ interesse por essa imagem dos livros no lixo, aqui, não reside no descaso de uma escola em particular, mas em como ela sugere que o prazer da leitura hoje, em certos contextos, esbarra na completa ausência de leitura e por vezes no desprezo do hábito literário. A imagem também sugere uma conclusão negativa sobre a possibilidade de permanência do interesse por robinsonadas literárias de funções pedagógicas. Seja como for, a família educativa dos Robinsons já ia mesmo apontando, com Júlio Verne, para novos rumos.

A escola dos Robinsons conta a história de um rapaz, Godfrey Morgan, que, antes do casamento, deseja conhecer o mundo. Cansado das facilidades de uma vida abastada e sem conflitos, ele alimenta a fantasia de ser um Robinson, personagem que conhece das leituras de Defoe e Wyss, citados no texto. Com esse desejo, está mais ou menos anunciado o enredo. Pouco depois da partida, o navio em que se encontra e com o qual daria uma volta ao mundo vai a pique e ele acaba náufrago solitário numa ilha desconhecida, apenas acompanhado do seu professor de etiqueta, que vale pouco nestas circunstâncias. Os dois companheiros passam cinco meses isolados até que, no capítulo final, tudo se resolve e uma série de mistérios acumulados desde o início da viagem é esclarecida. O tio do protagonista, um homem riquíssimo, havia armado um grande teatro: ele comprou uma ilha, mobilizou uma equipe, do capitão do navio, que em verdade nunca naufragara, ao pseudosselvagem que nessa 
peça interpretou Sexta-Feira, para que o seu sobrinho aprendesse com a aventura a dar valor, enfim, ao que possui. Com o fim do livro, como se vê, sobressai um sentido moral. No decurso da história, porém, ele é discreto e não compete em atenção com a sequência de ações relativamente independentes e empolgantes. Esta é a primeira diferença notável entre o texto de Júlio Verne e os de Defoe e Wyss. Ou seja, no romance de Júlio Verne há um sentido moral que organiza o todo, mas, à diferença do que ocorre em Defoe ou Wyss, ele não interrompe a ação e nem se manifesta a cada passo. Outra particularidade é que os personagens de Júlio Verne, embora encontrem soluções para as dificuldades da vida na ilha, sofrem no processo embaraços duráveis. Às vezes as soluções nem mesmo partem deles. Por exemplo, eles ficam boa parte da estadia na ilha sem fogo e sem alimentos cozidos, até que uma tempestade de raios finalmente lhes dá a solução. Se, portanto, as dificuldades na história de Júlio Verne têm a função de legitimar o arrependimento da imprudência inicial do protagonista à maneira de Defoe, elas modificam, além disso, o andamento com um acréscimo de interesse para o leitor, que presumivelmente não se enfada como em Wyss da sequência batida de soluções após soluções. O narrador evidencia a consciência com que explora esse recurso:

É preciso concordar que, se decididamente a má fortuna tinha convertido em Robinsons esses dois sobreviventes do Dream [nome do navio], mostrava-se para com eles muito mais rigorosa do que o fora para com os seus antecessores. A estes sempre tinham ficado quaisquer restos do navio que naufragara. Depois de terem feito com eles muitos objetos de primeira necessidade, podiam utilizar-lhes ainda os fragmentos. Em outros casos salvavam-se alimentos que chegavam para algum tempo, roupa, utensílios quaisquer, armas, coisas enfim com as quais se podia prover às exigências mais elementares da vida. Aqui, porém, nada disso! No meio das trevas da noite o navio desaparecera nos abismos do mar, sem deixar no recife o menos dos seus vestígios! Coisa alguma se tinha podido salvar, nem sequer um fósforo; e nesse momento era na realidade um fósforo que mais fazia falta. (VERNE, [18--?], p. 92).

Como se vê, junto ao investimento nas dificuldades, acresce possivelmente o interesse da leitura também a maneira como Júlio Verne faz das histórias de Defoe, Wyss e demais companheiros de robinsonadas 
um plano ficcional pressuposto, que se contrapõe à realidade suposta em sua própria narrativa. Essas referências à tradição dos Robinsons incentivam as comparações e a constatação de muitas reduções em $A$ escola dos Robinsons, por exemplo, nos catálogos, na reflexão e mesmo nas atividades da ilha que, por sinal, aumentam na passagem do livro de Defoe ao de Wyss. De um lado, essas reduções provavelmente contribuem para um efeito prazeroso longevo no texto de Júlio Verne, que assim evita "ruídos" ou preserva de interferências maiores o dinamismo tão bem tramado pelo domínio do narrador em produzir suspenses e lances cômicos - a qualidade humorística de Júlio Verne é um dos aspectos que revela esse domínio e não pode ser menosprezada na comparação com os antecedentes sérios em Defoe e Wyss. De outro lado, contudo, excelências à parte, ao se afastar daquela moralidade assertiva que se vê no exemplo de Wyss e apontar para um progresso específico da tradição discursiva da robinsonada rumo à literatura de entretenimento que se desenvolve tecnicamente, a narrativa de Júlio Verne em $A$ escola dos Robinsons também se afasta de certo modo da economia construtiva do Robinson original de Defoe, mais instigante em sua alternância de aventura arriscada, cotidiano e reflexão. Esta forma de redução não significa um juízo definitivo sobre as robinsonadas vernianas nem dissocia Júlio Verne de uma literatura complexa, antes pelo contrário. A vasta obra de Júlio Verne é feita de complexidades diversas e, além disso, contribuiu para a produção, nas gerações seguintes, de complexidades literárias ainda maiores. Os seus textos reúnem camadas e camadas de repertório literário e científico, e fazem falar muitas vozes, tal como observou Foucault (1969, p. 13), "vozes diferentes, superpostas, obscuras, e em confronto e contestação umas com as outras". Foucault distinguiu a concorrência nos romances de Júlio Verne de "fábula" (a história que se conta) e "ficção" (os regimes com que se contam a história), e viu nessa ficção "todo um teatro de sombras", discursos mais ou menos visíveis, narradores desdobrados em figuras narrativas que se aproximam ou se distanciam das matérias narradas, com esta ou aquela voz, modulada segundo este ou aquele conhecimento. Talvez por esse motivo, porque as aventuras de Júlio Verne não apenas primam pela construção, mas também dramatizam muitos conteúdos, sua leitura esteja na base de tantos autores, incluindo muitos modernistas, que tiveram nelas uma alternativa à ação realista burguesa mais doméstica. É interessante: assim como o autor de Ulisses, romance modernista por excelência, declarou sua admiração por Defoe 
(JOYCE, 1994), também modernistas (lato sensu), finisseculares ou já avançados no século XX, como Arthur Rimbaud, Alfred Jarry, Villiers de L'Isle-Adam, Joris-Karl Huysmans, Léon Bloy, Marcel Proust, Blaise Cendrars, Raymond Roussel, Jean Cocteau e Georges Perec, para citar apenas casos franceses e verificados (SAVIN, 2005), foram marcados por Júlio Verne. O mesmo deve ter ocorrido com Jean Giraudoux, autor de Suzana e o Pacifico, uma instigante robinsonada modernista de 1921, que encaminha os últimos exemplos aqui.

Suzana e o Pacifico, de Jean Giraudoux, é uma conjunção curiosa de Júlio Verne, Alice in Wonderland e decadentismo à la Huysmans, quer dizer, uma conjunção de aventura com uma sensibilidade excessiva e uma estesia preciosa. Júlio Verne e a personagem de Lewis Carrol são nominalmente lembrados no texto de Giraudoux, a exemplo de outros muitos autores, que compõem o amplo repertório da protagonista Suzana, uma francesa que se vê isolada numa ilha polinésia após o naufrágio resultante não só de tempestade mas também de um motim no navio que a levava à Austrália. Aliás, chama a atenção, desde o início, a personagem e narradora feminina, incomum nesta escola. Não por isso a história de Suzana deixa de ter uma perspectiva cuja impressão é mais ou menos masculina, assim como o isolamento na ilha do Pacífico, embora modifique a personagem, não faz dela uma ex-europeia. Este é, contudo, outro assunto. A contribuição específica de Suzana e o Pacífico aqui, considerando a tradição discursiva dos Robinsons, é ser uma robinsonada altamente subjetiva e até certo ponto esteticista. Para compreender esse aspecto, vale a pena ler o trecho no qual Suzana vê, pela primeira vez, a "sua" ilha:

Ela saía da bruma. Mil arco-íris levantados ou pousados de viés ligavam as enseadas aos outeiros. Pequenos bosques de palmeiras, pontuados de folhagens carmesins, rutilavam no vapor d'água, mais imóveis do que o zinco... Ouvi, subitamente, como o ruído dos repuxos que são abertos de dia, o rumor das cascatas... Cada árvore libertava o pássaro vermelho ou dourado que guardara durante a noite como penhor da aurora; e, a dez metros de mim, eu via já reunido - para que todo o mal-entendido a esse respeito fosse dissipado no primeiro momento entre a Providência e eu - quase ao alcance de minha mão, como o almoço junto de uma pessoa adormecida, tudo quanto poderia aplacar minha fome e minha sede. Bananeiras, oferecendo em redor milhares de bananas, 
como milhares de alças, das quais se rompia delicadamente a mais bonita, com a bondade de um cirurgião que rompe uma costela, feliz também pelo estalido; coqueiros mais altos do que carvalhos, cujos frutos tombavam sobre musgo ou sobre estalagmitas que os rebentavam; mangueiras, e a primeira manga que colhi estava exatamente no ponto. Durante milhares de anos a corrida entre meu destino e o daquela manga tinha sido regulada com exatidão. Um belo sol perambulava entre os fetos e as palmas como uma cozinheira. Ou então, com seus raios separados e cruzados como os pauzinhos de um chinês que comesse, perseguia e me revelava pequenos ananases e morangos enormes. (GIRAUDOUX, 1958, p. 48).

É notável como a banana que se destaca do cacho não é a mais saborosa, senão a mais bonita das bananas. São admiráveis os estímulos sensoriais para a impressão do paraíso ameno e dadivoso, além de artístico. A menção à Providência é uma lembrança de Defoe, mas também marca a diferença central entre Suzana e o Pacífico e exemplos anteriores: não há sequer tarefas ou dificuldades para vencer, e isso dá o que pensar e sentir, transforma a estadia na ilha em observação, imaginação, recordação, reflexão, sensação, fruição e espera. A fruição em particular remete àquela atitude conhecida do personagem de Huysmans em "Às avessas: Suzana colecionando pérolas", estendendo biombos de plumas, em cujas malhas às vezes amarra pássaros vivos, ou domesticando um ornitorrinco. Nesse sentido, Suzana inclusive procura por conflito, provocando a natureza, provando frutos de aparência venenosa, cogumelos aparentemente perigosos, atentando contra plantas carnívoras, mas nada acontece, pois a natureza é favorável ao bem-estar de Suzana. Por isso, como se vê, a espera é central e não a ação. Mesmo as "aventuras" complementares da passagem de Suzana para as ilhas vizinhas não modificam o romance nesse respeito. Quer dizer, as ações não adquirem, neste romance, valor narrativo em si, a não ser por alterarem o estado e os pensamentos da protagonista. Por exemplo, a descoberta em uma das ilhas de vestígios de um Robinson anterior, episódio mais que interessante, que poderia surpreender novo fôlego, pouco transtorna o andamento. A ocorrência com força realmente de perturbar o andamento ao ponto de arrancar o leitor à subjetividade inclusiva e incessante de Suzana é a chegada, no oitavo capítulo, de corpos sem vida à praia. De certo modo esse acontecimento concilia os mundos subjetivo e objetivo representando 
a compreensão gradual de que a Europa está em guerra (os cadáveres na praia são vítimas de uma batalha naval entre Alemanha e Inglaterra). Ou seja, se até então o paraíso polinésio resistia à vontade de conflito de Suzana, a Europa agora traz o conflito. O resgate de Suzana, feito por ingleses, ainda alegoriza as nações aliadas, conferindo sentido menos individual à protagonista de Giraudoux. Mesmo assim, o efeito geral do romance, pressupondo a distribuição desigual das constantes formais da tradição dos Robinsons, indica, neste capítulo radicalmente subjetivo da escola, que assim reage também à tendência para a aventura que ela vinha fixando com Júlio Verne e outros, um "desvio" no sentido reflexivo, o que não faz de Suzana e o Pacífico uma narrativa ruim, mas incrementa a sua distância de Defoe, que se desenvolve mais ainda nos dois próximos exemplos.

Até aqui foram consideradas uma continuação, o segundo Robinson de Defoe, e três robinsonadas ou textos que repetem a situação primeira do náufrago isolado mediante variações. Outro gênero de reposição da escola é o que restitui e atualiza a história de Defoe completando algum aspecto menos ou nada contemplado no original e revisando os acontecimentos. Em meados do século XX, mais especificamente entre o pós-guerra e Maio de 68, surgiram duas dessas revisões bastante opostas entre si nos seus propósitos e resultados: a mais conhecida em 1967, Sexta-Feira ou os limbos do Pacífico, de Michel Tournier; a menos conhecida hoje, mas um sucesso então, em 1955, A vida sexual de Robinson Crusoé, de Michel Gall. Esses dois títulos, embora discrepantes, parecem entretanto próximos em mais de um ponto, não só porque reescrevem a história de Robinson como quem dá a sua versão corrigida, devolvida à suposta verdade, mas também porque levam às últimas consequências elementos construtivos fundamentais para a consolidação do texto paradigmático de Defoe. Em Michel Tournier, a reflexão; em Michel Gall, a sensação, por assim dizer, o estímulo enfático ao prazer da leitura aguçado não como em Giraudoux via estesias sutis, mas por obscenidades representadas sem muito apuro. A comparação de um e outro seria indevida somente se não distinguisse a ampla superioridade do texto de Tournier sobre o de Gall. A vida sexual de Robinson Crusoé consiste num perfeito exemplo kitsch, no sentido que Hermann Broch (1975) atribuía ao termo, isto é, como redução da experiência, como composição dogmaticamente baseada na produção de efeitos e como deformidade menos estética do que ética. Contudo, no outro polo, o Robinson filosófico de Tournier, com 
suas qualidades e interesse, não faz tampouco justiça às expectativas da escola dos Robinsons tal como surgem aqui. Mesmo que seja um bom romance e proponha a discussão dos valores colonialistas (esboçada em Giraudoux), mesmo que faça de Sexta-Feira um personagem e tanto, ao insistir como insiste na especulação e na autoanálise, no contexto das realizações históricas dessa escola, ele não deixa de intensificar um extravio na organização formal e na articulação dos efeitos potenciais como se veem em Defoe. Em síntese, tanto o autor de Sexta-Feira como o da Vida sexual, guardadas as diferenças, sobrecarregam a narração de suas histórias de propósitos extraliterários, quer dizer, de alguma forma submetem suas histórias a conteúdos externos e não fazem derivar esses conteúdos modificados pelas histórias que contam. Nesse sentido, talvez fiquem mais próximos de $O$ Robinson suíço do que de Júlio Verne, por estranho que pareça ainda aproximar a família carola e ilustrada imaginada pelo pastor Wyss do pensador radical de Tournier e do pervertido imoral de Michel Gall.

Esses últimos exemplos devem servir, em contraste com um último título, para encaminhar a conclusão, delineando mais precisamente a ideia de fundação discursiva em Defoe, segundo aquela concepção de Foucault, e a questão do prazer na leitura da escola dos Robinsons. O título derradeiro em questão é $A$ invenção de Morel (1940), de Adolfo Bioy Casares. Na perspectiva deste ensaio, o título de Bioy Casares apresenta vantagens não apenas sobre os títulos de Michel Gall e Tournier, mas também sobre os outros discutidos anteriormente, como representante legítimo da escola discursiva dos Robinsons. A breve narrativa fantásticorealista não mostra correspondência imediata com o Robinson de Defoe. $A$ invenção de Morel conta a história de um fugitivo que procura abrigo numa ilha que ele descobre habitada por imagens tridimensionais como consequência do funcionamento de um aparelho inventado por este Morel que se lê no título. Aliás, o título do romance e o tema fantástico-científico lembram, antes, The Island of Doctor Moreau (1896), de H. G. Wells. Não é, portanto, uma correção de Defoe e seguidores e nem precisamente uma robinsonada, ainda que se encontrem aí características dessa tradição, ou alguns "signos característicos", para voltar à ideia de Foucault (2006, p. 281): o reconhecimento da ilha, a preocupação com alimento e conforto, a contagem do tempo por incisões numa árvore, a redação de um diário, a solidão. O lugar porém que esses elementos ocupam no livro de Bioy Casares, as diferenças que estabelecem, bem como a falta de outros 
elementos característicos, ainda que sejam determinantes para reconhecer de um modo ou de outro a familiaridade do título, não permitem um alinhamento simples com a escola dos Robinsons. As correspondências de $A$ invenção de Morel com o texto original de Defoe se dão em um nível superior. Por exemplo, o motivo da técnica, o domínio da técnica pelo homem e da natureza por conseguinte. No caso do personagem de Bioy Casares, em vez de assegurar a vida como em Defoe e escola, a conquista da técnica leva à morte, ou seja, a compreensão da invenção de Morel, do funcionamento da máquina e do fato de que ela consome a vida daqueles que registra, leva, no fim do livro, à decisão pela morte, à escolha do personagem por se fazer registrar e integrar o mundo como representação da ilha. Esse desfecho sugere mais que outra inflexão na tradição dos Robinsons. As imagens que consomem o que representam são também um comentário sofisticado a essa tradição que sobrevive a suas fontes históricas e fictícias. Ao mesmo tempo, a ideia de uma ilha em que se repete continuamente uma única sequência de cenas que se dramatizam a cada vez como se fosse a primeira, e a opção do personagem de tomar parte enfim nessa repetição, incluir sua representação numa representação anterior, que ele modifica, aqui aludem à tradição dos Robinsons como metarrobinsonada. Não é tão complexo quanto instigante interpretar desse modo A invenção de Morel.

A maneira como Jorge Luis Borges leu $A$ invenção de Morel vem por fim ao encontro do sentido de sua inclusão devida na escola dos Robinsons. Borges viu em A invenção de Morel uma realização admirável porque a trama do fugitivo ilhado e das imagens fantasmáticas com as quais ele convive está ancorada em peripécia e imaginação rigorosas, como deveriam ser os enredos aventurescos que não se reduzem a um enfileiramento de episódios e as narrativas modernas que se contrapõem à tendência das histórias sem muito evento, no geral preferidas da crítica. Por esse motivo, A invenção de Morel assume um lugar notável na escola discursiva dos Robinsons. Dos exemplos discutidos, o romance de Bioy Casares talvez seja o que mais se aproxime do primeiro Robinson, porque, favorecendo a ação, não deixa de incluir no conjunto elementos que elevam sua qualidade narrativa. Numa palavra, à diferença das outras narrativas, ao invés de variar semelhanças, ele termina por assemelhar variações, isto é, próprio como é, deixa os outros exemplos, a despeito das distinções visíveis e dos desvios voluntários, mais parecidos entre si. Uma das razões para tanto é sua ambição artística. Porém não é isso o principal, 
afinal o romance de Giraudoux tem a mesma ambição. O que o romance de Giraudoux parece não ter é a mesma potencialidade de $A$ invenção de Morel no que respeita aos efeitos de prazer na leitura pressupostos nesta escola, que se mostram mais ou menos dependentes da economia formal inaugurada por Defoe. É justamente essa economia, que regula a aventura sem eliminá-la e escolhe suas durações entre ação e inação presumindo efeitos de leitura, a organização narrativa que se repete transformada em $A$ invenção de Morel e assim faz de Defoe, quem sabe, um fundador discursivo. Foucault, como se viu, negou a romancistas determinado tipo de fundação discursiva porque as continuidades inauguradas por eles se definiriam antes por semelhanças do que por diferenças. O romance de Bioy Casares, ao repor o romance de Defoe não aderindo a semelhanças de superfície, isto é, sem fazer uma robinsonada e sem reescrever os enredos imagináveis do Robinson original, mas instituindo diferenças que renovam o entendimento da escola em questão por dentro, quer dizer, reestruturando os seus princípios construtivos básicos em condições novas, é um exemplo que põe em causa o raciocínio de Foucault neste aspecto e possivelmente é só um entre mais exemplos ausentes aqui.

\section{Referências}

BONOMO, Daniel. Experimentum in insula: Robinson Crusoé nas origens do aborrecimento. Literatura e Sociedade, São Paulo, v. 22, n. 25, p. 117-131, jul./dez. 2017. DOI: https://doi.org/10.11606/issn.22371184.v0i25p117-131.

BORGES, Jorge Luis. Prólogo. In: CASARES, Adolfo Bioy. A invenção de Morel. Tradução de Sérgio Molina. 4. ed. São Paulo: Biblioteca Azul, 2016. p. 7-10.

BROCH, Hermann. Das Böse im Wertsystem der Kunst. In: BROCH, Hermann. Schriften zur Literatur 2. Frankfurt am Main: Suhrkamp, 1975. p. 119-156.

CASARES, Adolfo Bioy. A invenção de Morel. Tradução de Sérgio Molina. 4. ed. São Paulo: Biblioteca Azul, 2016. 
CUNHA, Gualter. Uma dupla direção da escrita em Daniel Defoe: The Farther Adventures of Robinson Crusoe, ou, alguns bons ensinamentos da má literatura. Revista da Faculdade de Letras do Porto, Porto, v. 6, p. 189-206, 1989. (Série de Línguas e Literaturas, II).

DEFOE, Daniel. As novas aventuras de Robinson Crusoe. Tradução de Virgílio Tenreiro Viseu. Torres Vedras: E-Primatur, 2017.

DEFOE, Daniel. Robinson Crusoe. Edição de Michael Shinagel. 2. ed. New York: Norton, 1994. (Norton Critical Edition).

DEFOE, Daniel. Robinson Crusoé. Tradução de Sergio Flaksman. São Paulo: Penguin Classics Companhia das Letras, 2011.

FOUCAULT, Michel. O que é um autor? In: FOUCAULT, Michel. Estética: literatura e pintura, música e cinema. Organização de Manoel Barros da Motta. Tradução de Inês Autran Dourado Barbosa. 2. ed. Rio de Janeiro: Forense Universitária, 2006. p. 264-298. (Ditos e Escritos, 3).

FOUCAULT, Michel. Por trás da fábula. In: FOUCAULT, Michel et al. Júlio Verne: uma literatura revolucionária. São Paulo: Documentos, 1969. p. 11-19.

GALL, Michel. A vida sexual de Robinson Crusoé. Tradução de Mirian Paglia Costa. 2. ed. São Paulo: Brasiliense, 1987.

GIRAUDOUX, Jean. Suzana e o Pacífico. Tradução de Nair Lacerda. São Paulo: Difusão Europeia do Livro, 1958.

HUNTER, J. Paul. Genre, nature, Robinson Crusoe. In: RICHETTI, John (ed.). The Cambridge Companion to "Robinson Crusoe". Cambridge: Cambridge University Press, 2018. p. 3-15. DOI: https:// doi.org/10.1017/9781107338586.002.

JOYCE, James. Daniel Defoe. In: DEFOE, Daniel. Robinson Crusoe. Edição de Michael Shinagel. 2. ed. New York: Norton, 1994. p. 320-323. (Norton Critical Edition).

MAHER, Susan Naramore. Recasting Crusoe: Frederick Marryat, R. M. Ballantyne and the Nineteenth-Century Robinsonade. Children's Literature Association Quarterly, [S.l.], v. 13, n. 4, p. 169-175, 1988. DOI: https://doi.org/10.1353/chq.0.0620. Disponível em: https://muse. jhu.edu/article/248614. Acesso em: 15 out. 2020. 
MILLER, J. Hillis. Reading. The Swiss Family Robinson as Virtual Reality. In: LESNIK-OBERSTEIN, Karín. Children's literature. New approaches. New York: Palgrave Macmillan, 2004. p. 78-92. DOI: https:// doi.org/10.1057/9780230523777_4.

NODIER, Charles. Introdução. In: WYSS R. [sic]. O Robinson suiço. Tradução de Rosa de Murillo. Paris: Rio de Janeiro: Livraria Garnier Irmãos, [18--?]. p. i-viii. 2 v.

ROSA, Hartmut. Beschleunigung. Die Veränderung der Zeitstrukturen in der Moderne. 2. ed. Frankfurt am Main: Suhrkamp, 2016.

SAVIN, Tristan. Les enfants du capitaine Verne. L'Express, Paris, 1 fev. 2005. Actualité, Culture, Livres. Disponível em: https://www.lexpress. $\mathrm{fr} /$ culture/livre/les-enfants-du-capitaine-verne_809817.html. Acesso em: 15 out. 2020 .

SEELYE, John. Introduction: The Swiss Family Robinson. Children's Literature Association Quarterly, 1990 Proceedings, p. 4-12, 1990. DOI: https://doi.org/10.1353/chq.1990.0003. Disponível em: https://muse.jhu. edu/article/457521. Acesso em: 15 out. 2020.

TOURNIER, Michel. Sexta-Feira ou os limbos do Pacífico. Tradução de Fernanda Botelho. 3. ed. Rio de Janeiro: Bertrand Brasil, 2001.

VASCONCELOS, Sandra Guardini. A formação do romance inglês: ensaios teóricos. São Paulo: Aderaldo \& Rothschild: Fapesp, 2007.

VERNE, Júlio. A escola dos Robinsons. Tradução de Assis de Carvalho. Lisboa: Livrarias Aillaud \& Bertrand; Rio de Janeiro: Livraria Franciso Alves, [18--?]. (Grande Edição Popular das Viagens Maravilhosas aos Mundos Conhecidos e Desconhecidos).

WYSS, R. [sic]. O Robinson suiço. Tradução de Rosa de Murillo. Paris: Rio de Janeiro: Livraria Garnier Irmãos, [18--?]. 2 v. 